\title{
ICONOGRAFIA
}

\section{O Brasil que não se vê}

\author{
Isabela Balduino' \\ Texto e imagem
}

Fotografias perpetuam momentos

e seus recortes capturam visões

Esta visão é de um Brasil embiocado, mas de um Brasil real.

Um Brasil que permanece vivo através da coletividade e criatividade

Um Brasil que gemina histórias em suas terras brutas

Que floresce através do suor e cuidado.

Suas multidões de cores

De flores, de peles, de saberes

Se juntam em suas diferenças

Em tecnologias de luta e resistência 


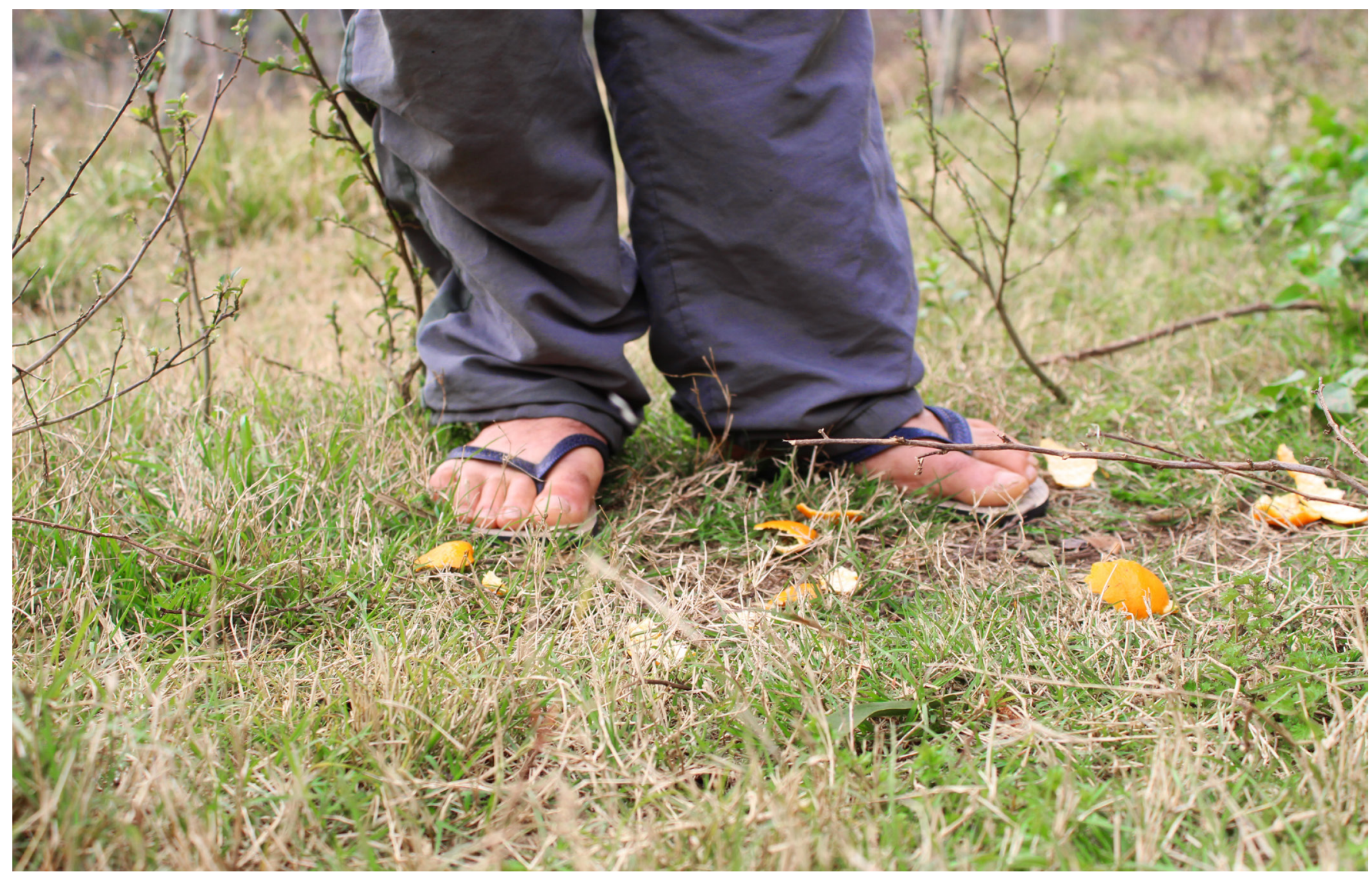

Economia e Desenvolvimento, v. 32, e11, 2020 


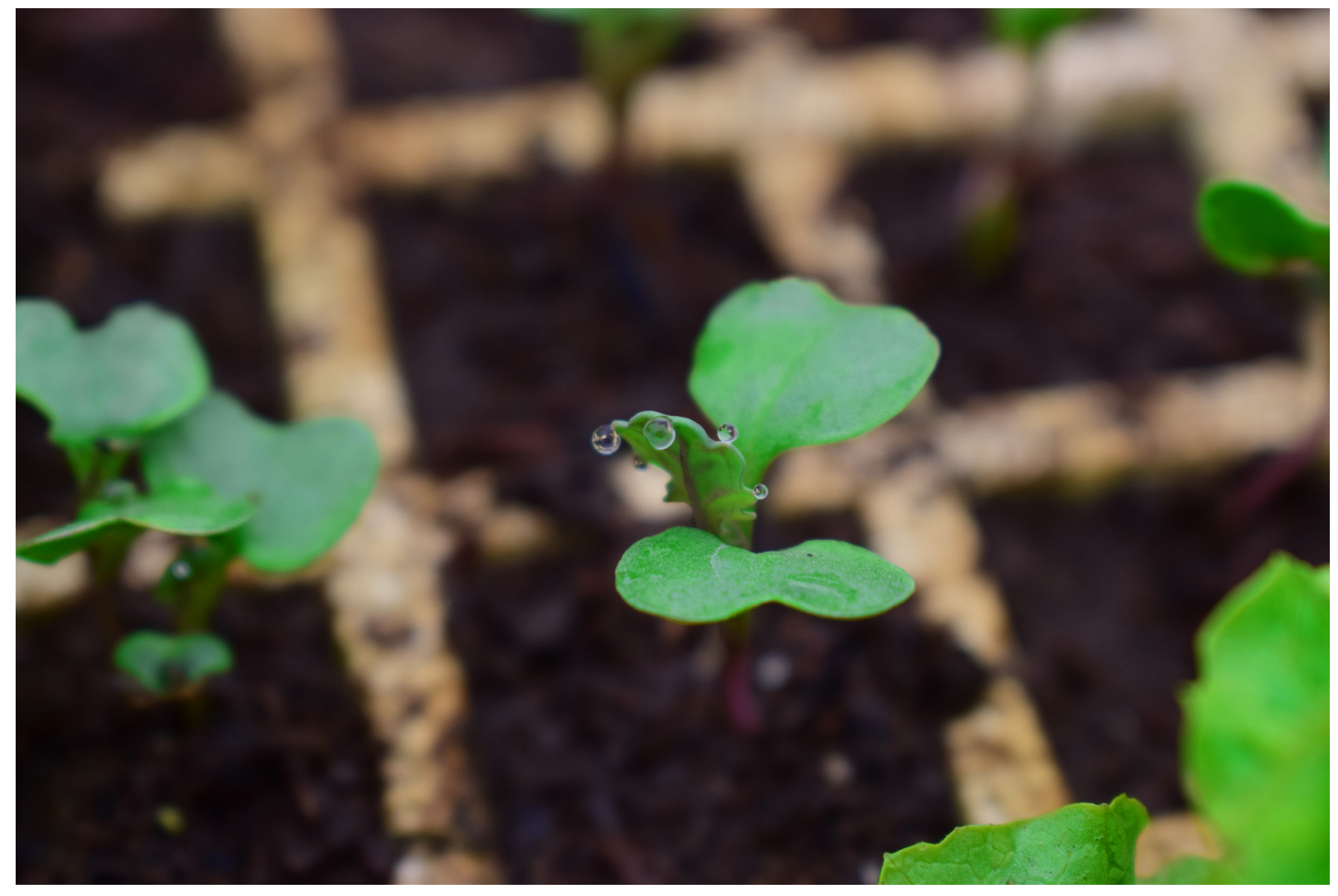

Economia e Desenvolvimento, v. 32, e11, 2020 


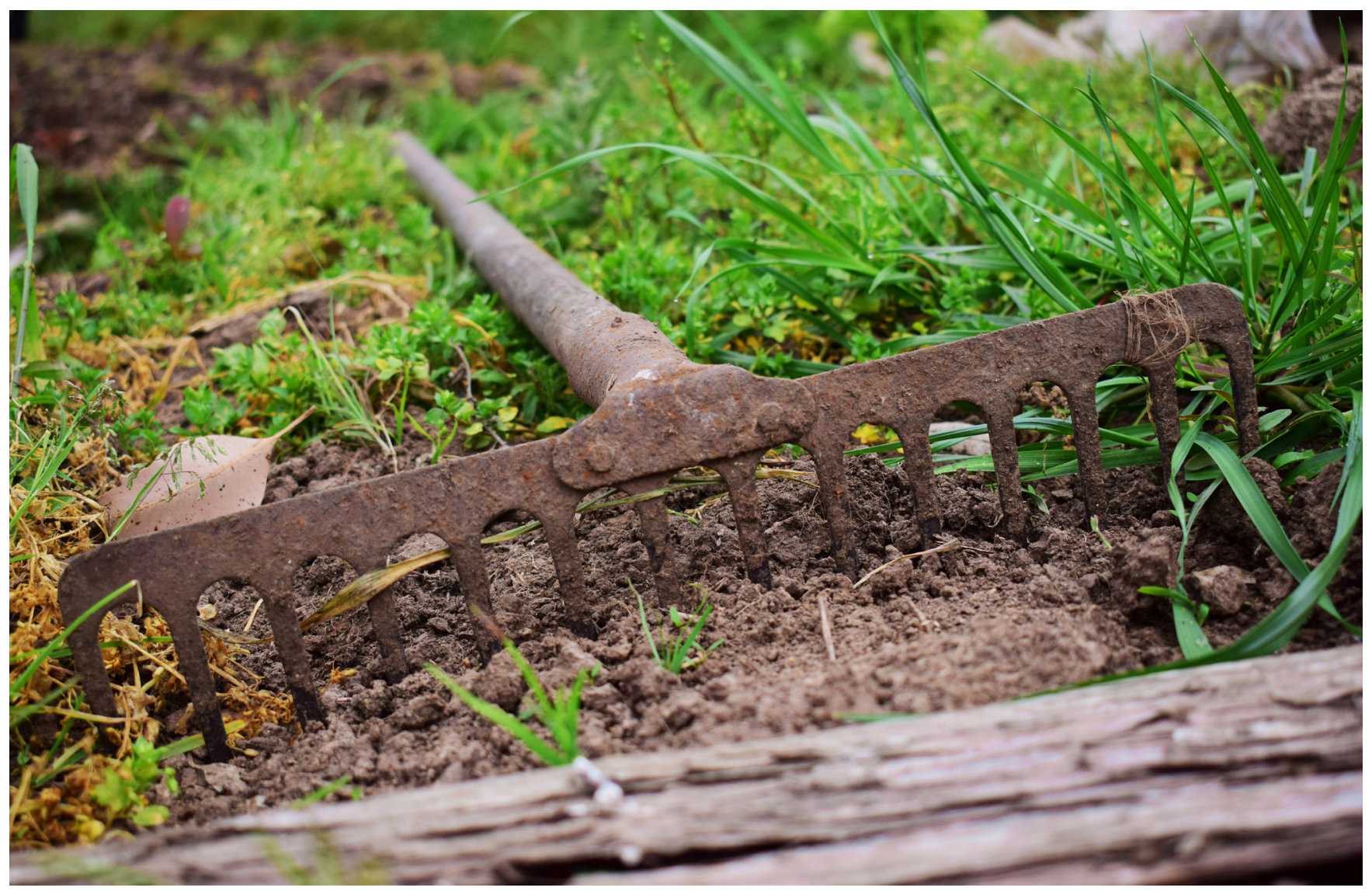

Economia e Desenvolvimento, v. 32, e11, 2020 


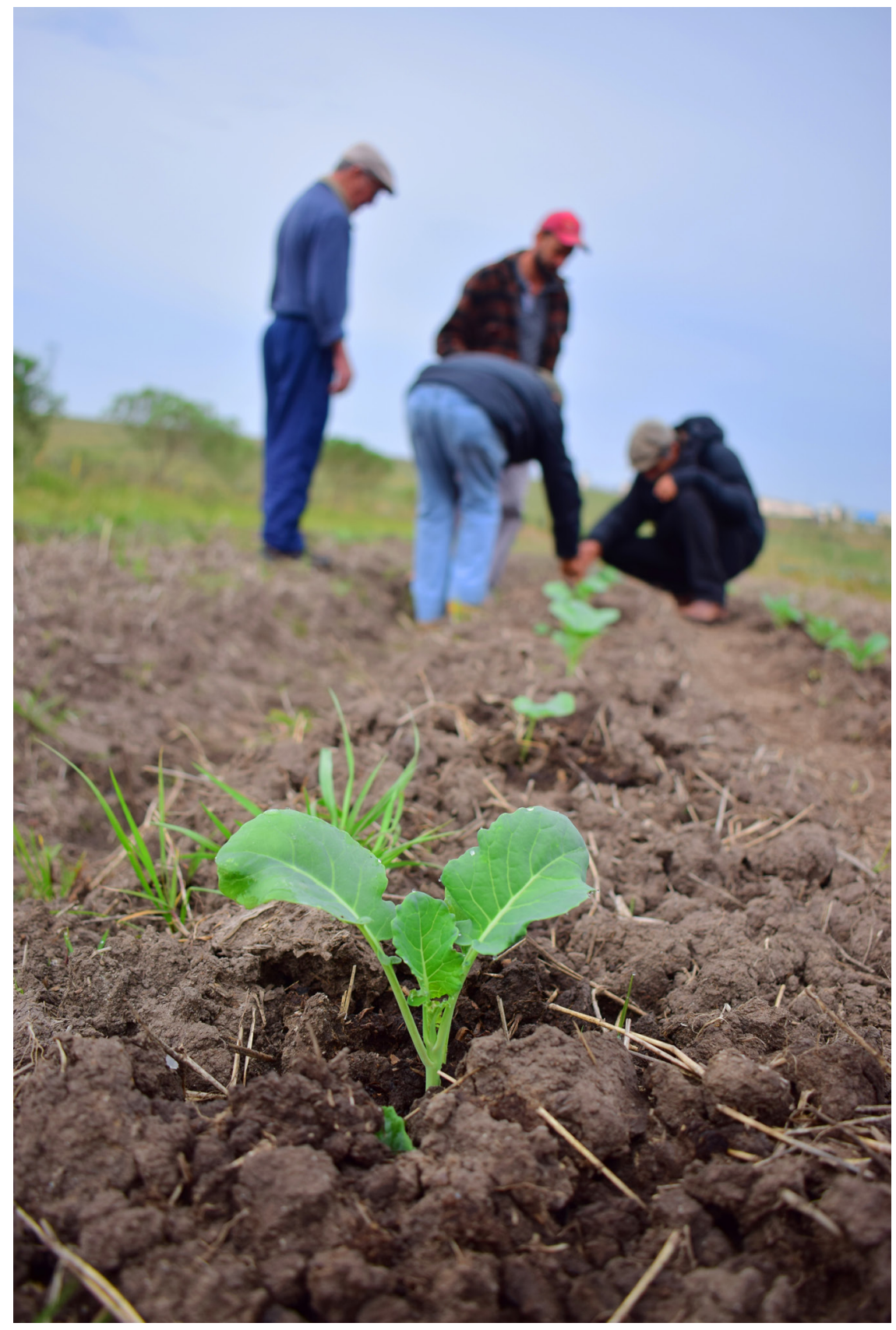

Economia e Desenvolvimento, v. 32, e11, 2020 


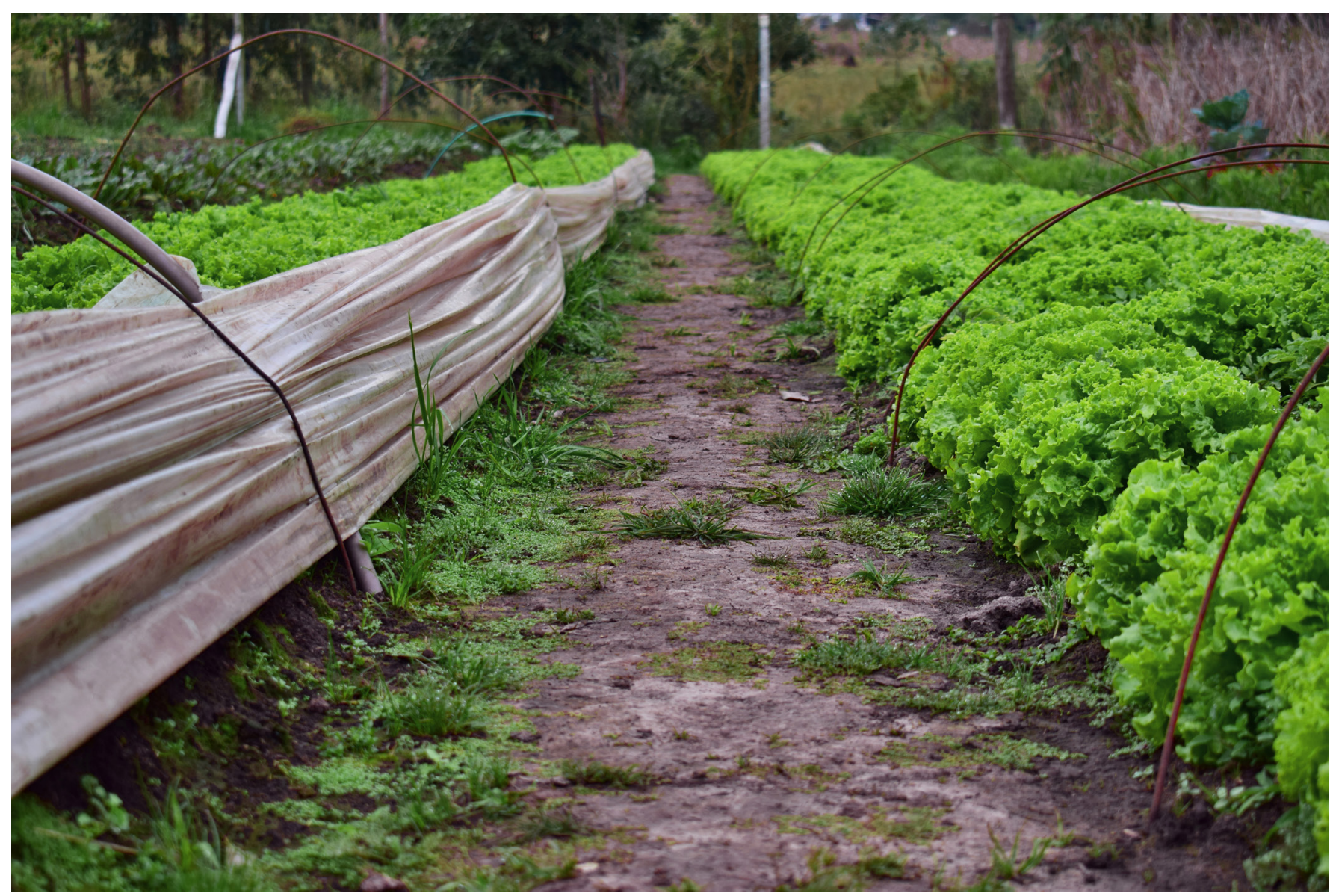

Economia e Desenvolvimento, v. 32, e11, 2020 


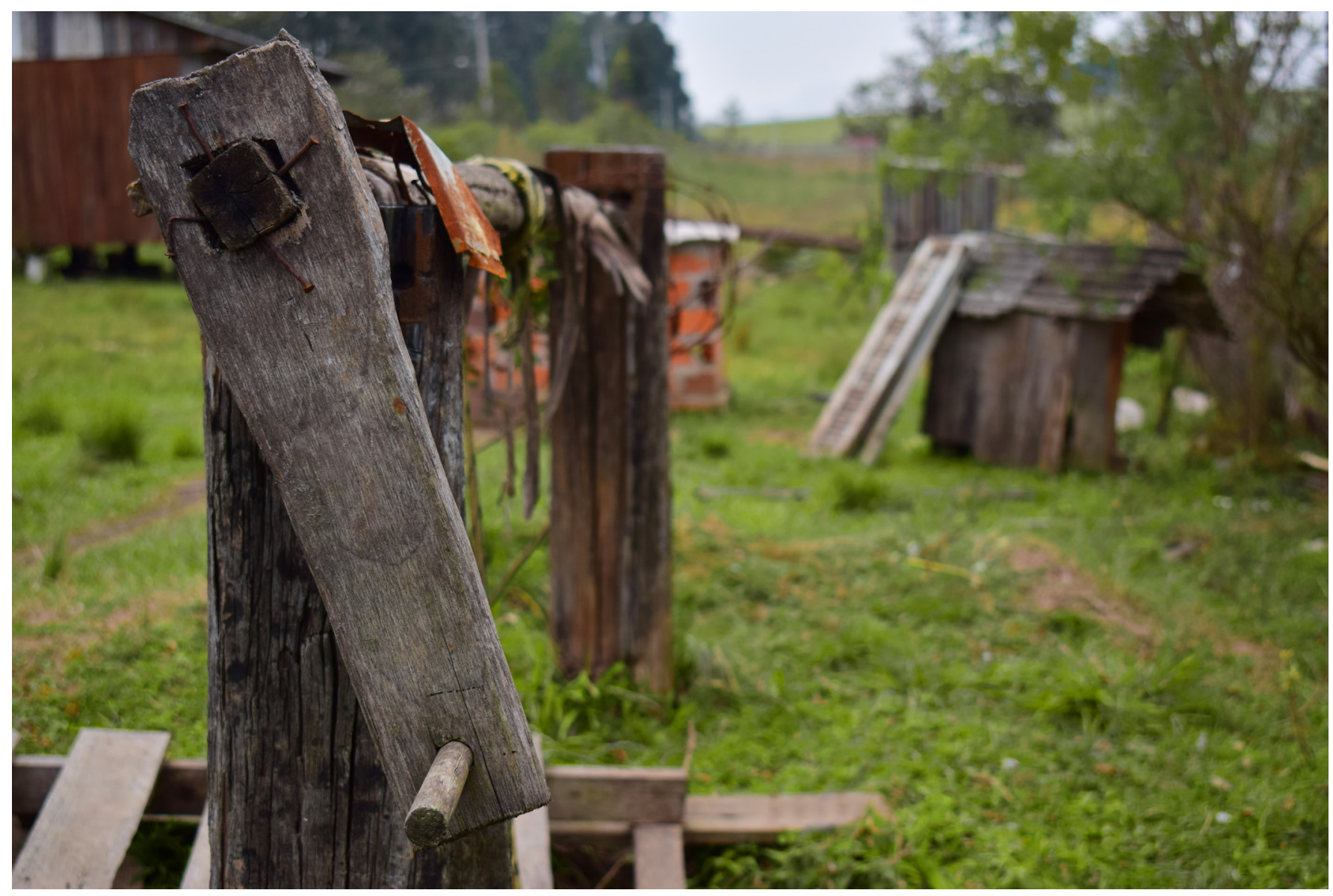

Economia e Desenvolvimento, v. 32, e11, 2020 


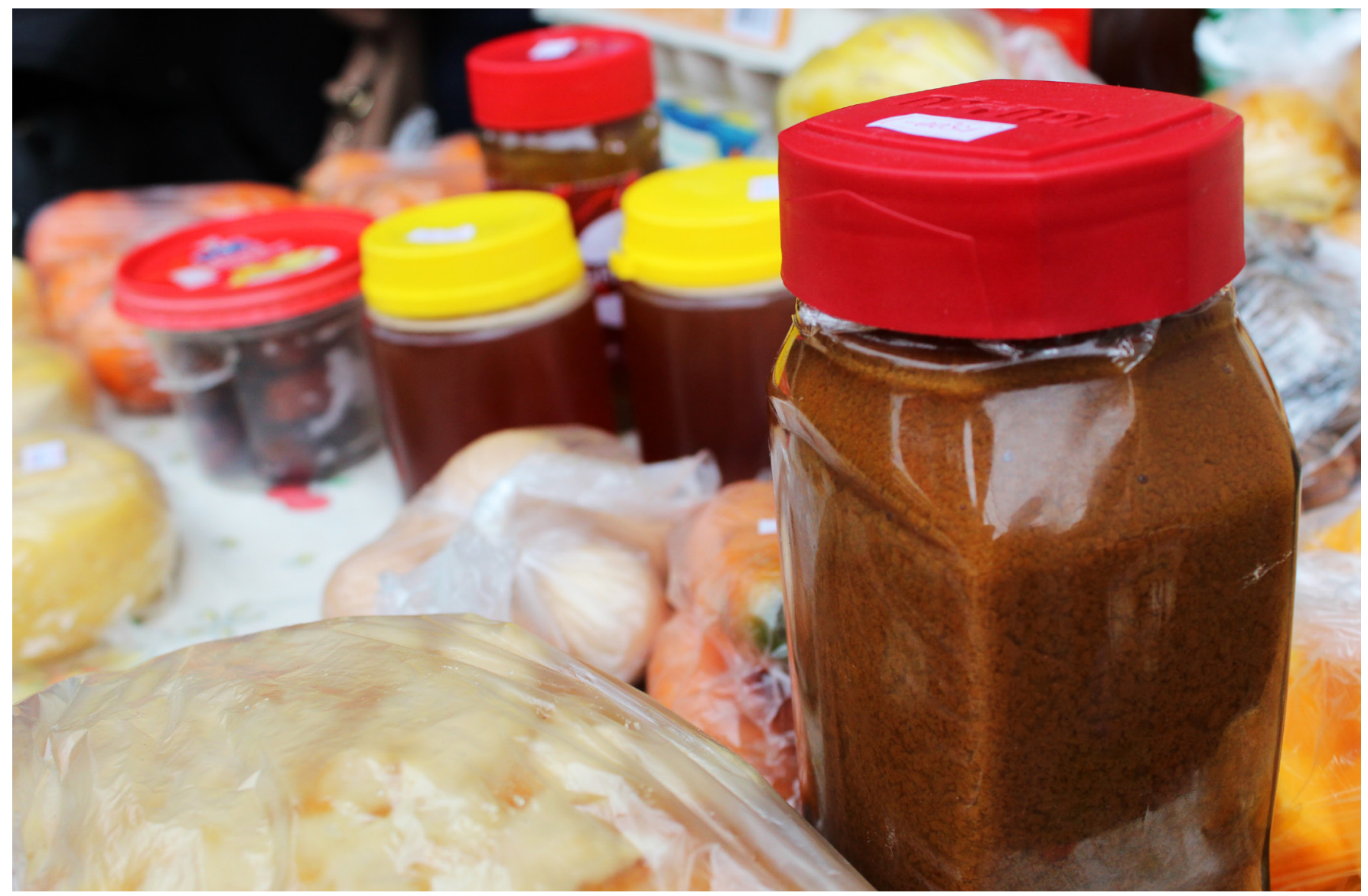

Economia e Desenvolvimento, v. 32, e11, 2020 